\title{
Pengaruh jumlah nozzle terhadap kinerja turbin pelton sebagai pembangkit listrik di Desa Sumber Agung Kecamatan Suoh Kabupaten Lampung Barat
}

\author{
Dwi Irawan ${ }^{1 *}$, Eko Nugroho², Eko Widiyanto ${ }^{3}$ \\ 1,2Jurusan Teknik Mesin Universitas Muhammadiyah metro \\ JI. Ki Hajar Dewantara No. 166 Kota Metro (0725) 42445-42454 \\ *Corresponding author: dwi_irawan12@yahoo.co.id
}

\begin{abstract}
A micro hydro power plant, or commonly known as a turbine is a power plant that utilizes the potential energy of water to be converted into mechanical energy which is then converted into electrical energy using a generator. The Pelton turbine is an extension of the impulse turbine with a split some blades dividing the jet into two equal beaks which are reversed sideways at the turbine wheel. This study aims to determine the effect of the number of nozzles to output power, efficiency, and electric power produced. In this study, a Pelton type water turbine was applied to a water source flowing from the mountains with a head of $26 \mathrm{~m}$ and $0.003167 \mathrm{~m}^{3} / \mathrm{s}$ water discharge. This study used 3 variations of the number of nozzles (single, double, and triple nozzle) with $9 \mathrm{~mm}$ outer diameter of nozzle and $35 \mathrm{~mm}$ nozzle length. The results of the research conducted, the turbine power is 419.53 watts, the turbine efficiency is $52 \%$, and the generator power is 360 Watts for triple nozzle variation. The turbine power obtained is 388.83 Watts, the turbine efficiency is $48 \%$, and the generator power is 234 Watts for double nozzle variation. And the power obtained is 367.47 Watts, the turbine efficiency is $45 \%$, and the generator power is 175 Watts for single nozzle variations.
\end{abstract}

\begin{abstract}
Abstrak
Pembangkit Listrik Tenaga Mikro Hidro (PLTMH) atau yang biasa dikenal dengan istilah turbin adalah pembangkit listrik yang memanfaatkan energi potensial air diubah menjadi energi mekanik untuk selanjutnya diubah menjadi energi listrik menggunakan generator. Turbin pelton merupakan pengembangan dari turbin impuls dengan pasangan mangkok-mangkok yang membelah membagi jet menjadi dua paruh yang sama yang dibalikkan menyamping pada roda turbin. Penelitian ini bertujuan untuk mengetahui pengaruh jumlah nozzle tehadap daya, efisiensi, dan daya listrik yang dihasilkan. Dalam penelitian ini dibuat turbin air jenis pelton yang diaplikasikan pada sumber air yang mengalir dari pegunungan dengan ketinggian $26 \mathrm{~m}$ dengan debit air $0,003167 \mathrm{~m}^{3} / \mathrm{s}$. Penelitian ini menggunakan 3 variasi jumlah nozzle dengan diameter luar nozzle $9 \mathrm{~mm}$ dan panjang nozzle $35 \mathrm{~mm}$. Dari hasil penelitian yang dilakukan yaitu pengujian daya turbin, efisiensi turbin, dan daya generator. Dari ketiga pengujian tersebut dengan menggunakan variasi 3 nozzle didapatkan daya turbin sebesar 419,53 Watt, efisiensi turbin sebesar 52\%, dan daya generator sebesar 360 Watt. Variasi 2 nozzle daya turbin yang didapat sebesar 388,83 Wat, efisiensi mekanik turbin sebesar 48\%, dan daya generator sebesar 234 Watt Dan variasi 1 nozzle daya turbin yang didapat sebesar 367,47 Watt, efisiensi turbin sebesar 45\%, dan daya generator sebesar 175 Watt.
\end{abstract}

Kata kunci: Turbin Pelton, nozzle, daya, efisiensi.

\section{Pendahuluan}

Krisis energi yang kita alami saat ini tidak dapat dipungkiri lagi, penyebab terjadinya krisis energi antara lain bisa disebabkan oleh kegiatan-kegiatan manusia menggali sumber yang ada di bumi [1]. Kebutuhan energi di Indonesia saat ini masih didominasi oleh energi yang berbasis 
bahan bakar fosil, seperti batu bara, gas alam, dan minyak bumi. Kerugian dari bahan bakar fosil ialah sifatnya yang tidak ramah lingkungan, karena hasil pembakaran bahan bakar fosil yaitu mengandung $\mathrm{CO}_{2}[2]$.

Turbin Pelton, sangat cocok digunakan untuk head tinggi juga penyemprotan air ke sudu turbin dapat menggunakan jumlah nozzle lebih dari satu buah agar mendapatkan tenaga yang lebih besar. Turbin Pelton termasuk jenis Turbin impuls yang perubahan energinya dilakukan di dalam nozzle dimana air yang semula mempunyai energi potensial yang tinggi diubah menjadi energi kinetik [3].

Nozzle adalah perangkat yang dirancang untuk mengontrol arah atau karakteristik dari aliran fluida (terutama untuk meningkatkan kecepatan) saat keluar (atau masuk) suatu ruang tertutup atau pipa. Nozzle merupakan pipa atau tabung yang bervariasi luas penampangnya, dan dapat digunakan untuk mengarahkan atau memodifikasi aliran cairan (cairan atau gas). Nozzle sering digunakan untuk mengontrol laju aliran, kecepatan, arah, massa, bentuk, dan atau tekanan dari aliran yang berbentuk cair maupun gas [3]. Penelitian perencanan turbin air mikro hidro jenis Pelton untuk pembangkit listrik yang telah dilakukan di Desa Pineleng, menghasilkan tinggi head mencapai 12 meter dengan kapasitas air (debit) 0,06 $\mathrm{m}^{3} / \mathrm{s}$, daya aktual yang dihasilkan turbin adalah 4,0 kW, dimana efisiensi total sebesar $60 \%$ berdasarkan kisaran penerapan turbin Pelton mikro [4].

\section{Tinjauan Pustaka}

Turbin secara umum dapat diartikan sebagai mesin penggerak mula dimana energi potensial yaitu air yang digunakan langsung untuk memutar roda turbin (roda jalan), dan diteruskan oleh poros generator guna untuk mengubah energi mekanik menjadi energi listrik. Dengan demikian turbin air dapat diartikan sebagai suatu mesin penggerak mula yang fluida kerjanya adalah air. [1]
Pembangkit Listrik Tenaga Mikro Hidro (PLTMH) adalah suatu instalasi pembangkit listrik tenaga air dengan kapasitas pembangkitan rendah. Pada prakteknya dengan kapasitas 5 sampai dengan $100 \mathrm{~kW}$. Beberapa klarifikasi lainnya secara umum mendefinisikan mikro untuk daya kurang dari $100 \mathrm{~kW}$ dan mini untuk daya antara $100 \mathrm{~kW}$ sampai dengan $5000 \mathrm{~kW}[5]$.

Turbin Pelton merupakan Turbin Impuls. Turbin Pelton terdiri dari satu set sudu jalan yang diputar oleh pancaran air yang disemprotkan dari satu atau beberapa nozzle. Turbin Pelton adalah salah satu dari jenis turbin air yang paling efisien. Turbin Pelton adalah turbin yang cocok digunakan untuk head tinggi. Pada Turbin Pelton energi potensial air berubah menjadi energi kinetik melalui nozzle disemprotkan ke sudu-sudu untuk dirubah menjadi energi mekanik yang digunakan untuk memutar poros generator. Turbin Pelton termasuk jenis turbin impuls yang merubah seluruh energi air menjadi energi kecepatan sebelum memasuki runner turbin. Perubahan energi ini dilakukan di dalam nozzle dimana air yang semula mempunyai energi potensial yang tinggi diubah menjadi energi kinetis. Pancaran air yang keluar dari nozzle akan mengenai runner sehingga runner akan berputar meneruskan energi kinetik ke energi mekanik untuk menghasilkan daya listrik dan kecepatan pancaran tergantung dari tinggi air di atas nozzle nya serta effisiensinya [6].

Penelitian tentang variasi nozzle turbin sebelumnya pernah dilakukan oleh Rosmiati dan Yani di tahun 2017, dengan variasi nozzle yaitu 1 inchi, $3 / 4$ inchi, $1 / 2$ inchi, dan $1 / 3$ inchi. Torsi turbin maksimum terjadi pada diameter nozzle $1 / 3$ inchi dengan nilai sebesar $0,645 \mathrm{Nm}$, kemudian torsi kedua pada diameter nozzle $1 / 2$ inchi dengan nilai sebesar $0,555 \mathrm{Nm}$, torsi turbin ketiga terjadi pada diameter nozzle $3 / 4$ inchi dengan nilai sebesar $0.345 \mathrm{Nm}$, dan torsi turbin terendah terjadi pada diameter nozzle 1 inchi dengan nilai sebesar 0,165 Nm. Daya turbin maksimum terjadi pada diameter 
nozzle $1 / 3$ inchi dengan nilai sebesar 5,966 Watt, kemudian daya turbin urutan kedua terjadi pada diameter nozzle $1 / 2$ inchi dengan nilai sebesar 5,338 Watt, kemudian daya turbin urutan ketiga terjadi pada diameter nozzle $3 / 4$ inchi dengan nilai sebesar 1,413 Watt [7].

Nozzle mempunyai peranan penting pada suatu istalasi turbin pelton. Apabila nozzle tidak bekerja dengan baik maka akan berpengaruh kepada daya yang dihasilkan turbin. Adapun fungsi dari nozzle adalah sebagai berikut [6]:

1. Mengarahkan pancaran air ke sudu turbin.

2. Mengubah tekanan menjadi energi kinetik.

3. Mengatur kapasitas air yang masuk turbin.

Pada nozzle terdapat jarum yang berfungsi untuk mengatur kapasitas dan mengkonsentrasikan air yang terpancar di mulut nozzle. Panjang jarum sangat menentukan tingkat konsentrasi air, makin panjang jarum air makin terkonsentrasi.

\section{Metode Penelitian}

Penelitian ini dilakukan di Desa Sumber Agung Kecamatan Suoh Kabupaten Lampung Barat, dengan menvariasikan jumlah nozzle yaitu 1, 2, dan 3 nozzle. Pipa penstok menggunakan pipa diameter 2 inchi. Ketinggian air jatuh $26 \mathrm{~m}$ dan debit air yang ada adalah $3,167 \mathrm{~L} / \mathrm{s}$.

Dalam prosedur pengujian alat, sebelum alat diuji atau diaplikasikan terlebih dahulu harus mempersiapkan tahap-tahapnya. Adapun tahap-tahapnya adalah sebagai berikut :

1. Mempersiapkan alat yang digunakan dalam pengujian.

2. Memasang nozzle pada pipa yang sudah dialiri air untuk mengetahui kecepatan aliran fluida yang di semburkan nozzle.

3. Mengukur putaran turbin dengan menggunakan tachometer.

4. Melakukan pengujian torsi.

5. Memasang dan menjalankan generator.

6. Melakukan pengujian daya listrik yang dihasilkan generator.
7. Mengulangi langkah 3, 4 dan 5 pada variasi jumlah nozzle yang lain.

8. Mengumpulkan dan mencatat data hasil pengujian.

9. Mengolah dan menganalisa data.

\section{Hasil dan Pembahasan}

Adapun hasil dan pembahasan dari penelitian ini adalah:

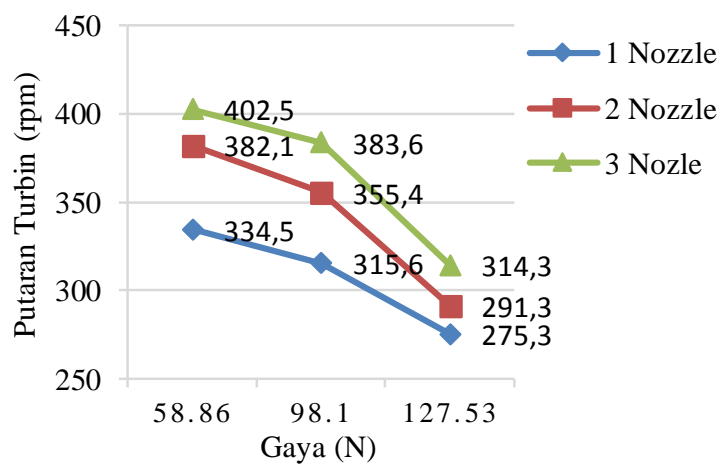

Gambar 1. Grafik hubungan gaya terhadap putaran turbin

Dari gambar 1 terlihat bahwa dari 3 sampai 1 nozzle grafik terlihat semakin menurun yaitu bisa dilihat dari variasi 3 nozzle putaran mencapai $402,5 \mathrm{rpm}$ dan pada variasi 1 nozzle putaran hanya mencapai 334,5 rpm. Hal ini didasarkan besarnya gaya yang diberikan pada turbin sehingga mempengaruhi putaran-putaran pada setiap variasi jumlah nozzle.

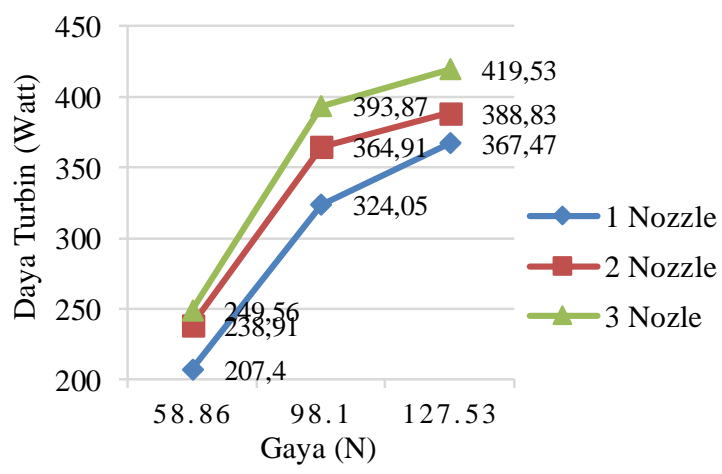

Gambar 2 grafik hububungan gaya terhadap daya turbin

Dari gambar 2, grafik hubungan gaya terhadap daya turbin dengan menggunakan tiga variasi jumlah nozzle yaitu dilakukan pada variasi 1 nozzle, 2 nozzle, dan 3 nozzle. Dapat diketahui dari 
variasi 1 nozzle sampai 3 nozzle dimana gaya semakin besar maka daya turbin yang dihasilkan juga akan bertambah, dapat dilihat pada variasi 1 nozzle dengan gaya paling besar yaitu pada 127,53 $\mathrm{N}$ daya turbin yang dihasilkan sebesar 367,47 Watt, dan pada variasi 3 nozzle dengan gaya yang sama seperti pada variasi 1 nozzle daya yang dihasilkan sebesar 419,53 Watt, dari hasil data tersebut dapat disimpulkan bahwa ketika gaya yang diberikan pada turbin bertambah maka daya yang dihasilkan turbin juga akan bertambah.

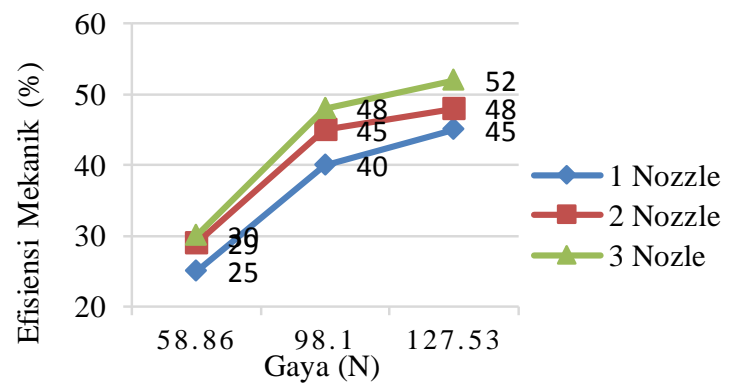

Gambar 3. Grafik Hubung Gaya Terhadap Efesiensi Mekanik Turbin

Dari gambar 3, terlihat bahwa semakin besar gaya bertambah maka semakin besar efesiensi mekanik turbin yang dihasilkan, karena dipengaruhi oleh besarnya daya turbin dan daya air. Efesiensi mekanik turbin akan bertambah dengan seiring besarnya gaya yang diberikan, setelah melakukan pengujian lapangan secara langsung disitu diketahui bahwa pada variasi 1 nozzle mendapat nilai efesiensi mekanik sebesar $45 \%$ sedangkan pada variasi 3 nozzle nilai efesiensinya sebesar 52\%. Dari data tersebut dapat disimpulkan bahwa jumlah nozzle dan besarnya gaya sangat berpengaruh pada efesiensi mekanik turbin.

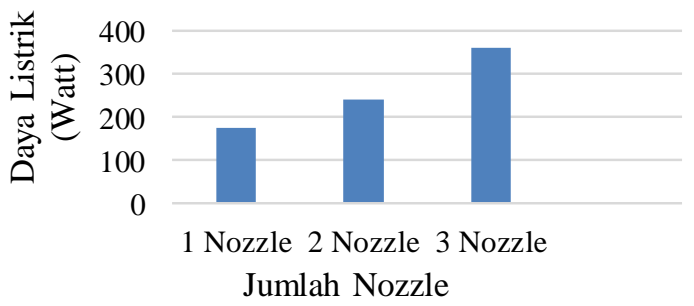

Gambar 4. Grafik pengaruh jumlah nozzle terhadap daya generator
Dari gambar 4, dapat diketahui variasi jumlah nozzle sangat berpengaruh terhadap daya listrik yang dihasilkan generator. Pada saat dilakukan variasi jumlah nosel yaitu pada variasi 1 nozzle, daya listrik yang dihasilkan generator sebesar 175 watt sedangkan pada variasi 3 nozzle daya yang dihasilkan generator sebesar 360 watt. Dari data tersebut dapat disimpulkan bahwa semakin banyak jumlah nozzle maka daya listrik yang dihasiklan generator akan semakin besar.

\section{Kesimpulan}

Berdasarkan data yang diperoleh dari hasil penelitian dan pengujian pada turbin pelton dengan pengaruh jumlah nozzle terhadap daya turbin, serta pengaruh jumlah nozzle terhadap efisiensi mekanik turbin, dan pengaruh jumlah nozzle terhadap daya listrik yang dihasilkan generator dengan 3 variasi jumlah nozzle yang berdiameter $9 \mathrm{~mm}$ dan panjang 35 mm maka dapat disimpulkan bahwa daya yang dihasilkan turbin pada variasi 1 nozzle yaitu 367,47 watt, dan variasi 3 nozzle daya turbin yang dihasilkan yaitu 419,53 Watt. Efisiensi mekanik turbin pada variasi 1 nozzle yaitu $45 \%$, dan pada variasi 3 nozzle yaitu 52\%. Daya listrik yang dihasilkan generator pada variasi 1 nozzle yaitu 175 watt, dan pada variasi 3 nozzle daya generatornya yaitu 360 watt.

\section{Referensi}

[1] M. Mafruddin and D. Irawan, "Pembuatan Turbin Mikrohidro Tipe Cross-Flow Sebagai Pembangkit Listrik Di Desa Bumi Nabung Timur," Turbo J. Progr. Stud. Tek. Mesin, vol. 3, no. 2, pp. 7-12, 2014.

[2] M. Mafruddin and D. Irawan, "Pengaruh Diameter Dan Jumlah Sudu Runner Terhadap Kinerja Turbin Cross-Flow," Turbo J. Progr. Stud. Tek. Mesin, vol. 7, no. 2, pp. 223-229, 2018.

[3] M. Mafruddin, R. M. Irawan, N. Setiawan, N. Rajabiah, and D. Irawan, 
"Pengaruh jumlah sudu dan diameter nozel terhadap kinerja turbin pelton," Turbo J. Progr. Stud. Tek. Mesin, vol. 8, no. 2, pp. 214-218, 2020.

[4] C. Poea, G. . Soplanit, and J. Rantung, "Pembangkit Listrik Di Desa Kali Kecamatan Pineleng Dengan Head 12 Meter," Tek. Mesin, pp. 1-9, 2013.

[5] W. Wijaya, J. Windarto, and K. Karnoto, "Analisa Perencanaan Pembangkit Listrik Tenaga Mini Hidro Di Sungai Logawa Kecataman Kedungbanteng Kabupaten Banyumas," Transient J. Ilm. ..., 2012.

[6] D. Irawan, "Prototype Turbin Pelton Sebagai Energi Alternatif Mikrohidro Di Lampung," Turbo J. Progr. Stud. Tek. Mesin, vol. 3, no. 1, pp. 1-6, 2014.

[7] Y. Rosmiati et al., "Pengaruh Variasi Diameter Nosel Terhadap," vol. 6, no. 1, pp. 1-10, 2017. 